\title{
ELECTRICITY INFRASTRUCTURE PLANNING: EVALUATING SOLAR POTENTIAL ASSESSMENTS FOR INFORMAL SETTLEMENTS USING GRASS AND FREELY AVAILABLE DATA
}

\author{
L. Hassim*, S. Coetzee, V. Rautenbach \\ Centre for Geoinformation Science, Department of Geography, Geoinformatics and Meteorology, University of Pretoria, South \\ Africa - u14033438@tuks.co.za, (serena.coetzee, victoria.rautenbach)@up.ac.za
}

\author{
Commission IV, WG IV/4
}

KEY WORDS: Solar Potential Assessment, Solar Power, Informal Settlement, GRASS GIS, Open Source Software, Open Data

\begin{abstract}
:
Informal settlements, also known as slums or shanty towns, are characterised by rapid and unstructured expansion, poorly constructed buildings, and in some cases, they are on disputed land. Such settlements often lack basic services, such as electricity. As a result, informal settlement dwellers turn to hazardous alternative sources of energy, such as illegal electricity connections and paraffin. Solar power is a clean and safe alternative. However, informal settlements are often located on undesirable land on the urban fringe where the topography may hinder the use of solar energy. The high density of dwellings could also be a hindrance. Therefore, the solar potential needs to be assessed before any implementations are planned. Solar potential assessment functionality is generally available in geographic information system (GIS) products. The nature, cost and accessibility of datasets required for the assessment vary significantly. In this paper, we evaluate the results of solar potential assessments using GRASS (Geographic Resources Analysis Support System) for a number of different datasets. The assessments were done for two informal settlements in the City of Tshwane (South Africa): Alaska, which is nestled on a hill; and Phomolong, a densely populated settlement with a rather flat topography. The results show that solar potential assessments with open source GIS software and freely available data are feasible. This eliminates the need for lengthy and bureaucratic procurement processes and reduces the financial costs of assessing solar potential for informal settlements.
\end{abstract}

\section{INTRODUCTION}

In South Africa, informal settlements are a common occurrence due to rapid urbanization and lack of affordable housing (Richards et al., 2006). These settlements are often located in areas that are unoccupied and/or difficult to develop, and the dwellings are constructed from any available material, such as corrugated iron (Rautenbach et al., 2015). Because informal settelements emerge spontaneously, they lack infrastructure for basic services, such as running water, storm water drainage and electricity (Paar and Rekittke, 2011; Richards et al., 2006; Sliuzas, 2003). Therefore, informal settlement dwellers turn to hazardous alternatives, such as illegal electricity connections, which frequently result in electrocutions (Fuzile, 2017; Moodley, 2016). The illegal connections also contribute to the municipality's debt, as the cost of electricity used in the settlement cannot be recovered. Municipalities regularly dispatch inspectors to remove illegal connections, but this solution is usually short-lived. Additionally, the removal of illegal connections has led to service delivery protests (Dawood, 2015; Khubisa, 2017).

Solar power is a potential solution to these challenges. The initial costs of solar photovoltaic (PV) panels is significant, but dwindles in comparison to the installation of underground wiring from an electrical substation connected to customary electricity infrastructure (Devabhaktuni et al., 2013). Solar power could be a long-term inexpensive means for providing the residents of an informal settlement with electricity (Holm, 2006) suggest that solar power could facilitate poverty reduction.

Prior to implementation, solar potential in the area must be assessed to determine whether solar panels are feasible (Fluri, 2009). In urban environments, space limitations and obstructions to incoming sunlight constrain solar potential. Informal settlements have unique challenges due to the nature and density of dwellings and the shades that these cast (Rautenbach et al., 2015). Models and methods for describing the physical behaviour of solar radiation have significantly improved in recent years. Today, user-friendly detailed analysis and representation of radiation phenomena are possible, making solar potential assessments accessible to users outside the traditional architecture and engineering niches (Freitas et al., 2015).

A solar potential assessment determines the amount of solar radiation in an area (Gupta et al., 2012). A number of software products, e.g. GRASS, ArcGIS or PVSyst and datasets, e.g. a digital elevation model or LiDAR, are available for this. For example, Hofierka and Kanuk (2009) proposed a methodology for the assessment of solar potential in urban areas using free, open source solar radiation tools and a 3-D city model. The research reported in this paper aimed to find a financially and practically feasible solution for assessing solar potential in informal settlements.

We present the results of an evaluation of solar potential assessments using GRASS with different datasets: a freely

\footnotetext{
Corresponding author
} 
available 30m digital elevation model (DEM); the same DEM resampled to a $2 \mathrm{~m}$ and $10 \mathrm{~m}$ digital surface model (DSM); and a $1 \mathrm{~m}$ LiDAR DSM procured by the City of Tshwane (CoT) Metropolitan Municipality. The remainder of the paper is structured as follows: in Section 3 the method is described; in Section 4, the results are presented and discussed; followed by a conclusion in Section 5.

\section{METHOD}

The process followed for this evaluation was informed by related work in Chaves and Bahill (2010), Freitas et al. (2015), Fluri (2009), Redweik et al. (2013), Liang et al. (2015). It incorporates considerations for informal settlements discussed by Owen and Wong (2013), Kakembo and van Niekerk (2014) and Rautenbach et al. (2016). The flowchart in Figure 1 illustrates the process. The remaining parts of this section describe steps 1 to 4 of the process. Steps 5 and 6 are presented in sections 4 and 5 respectively.

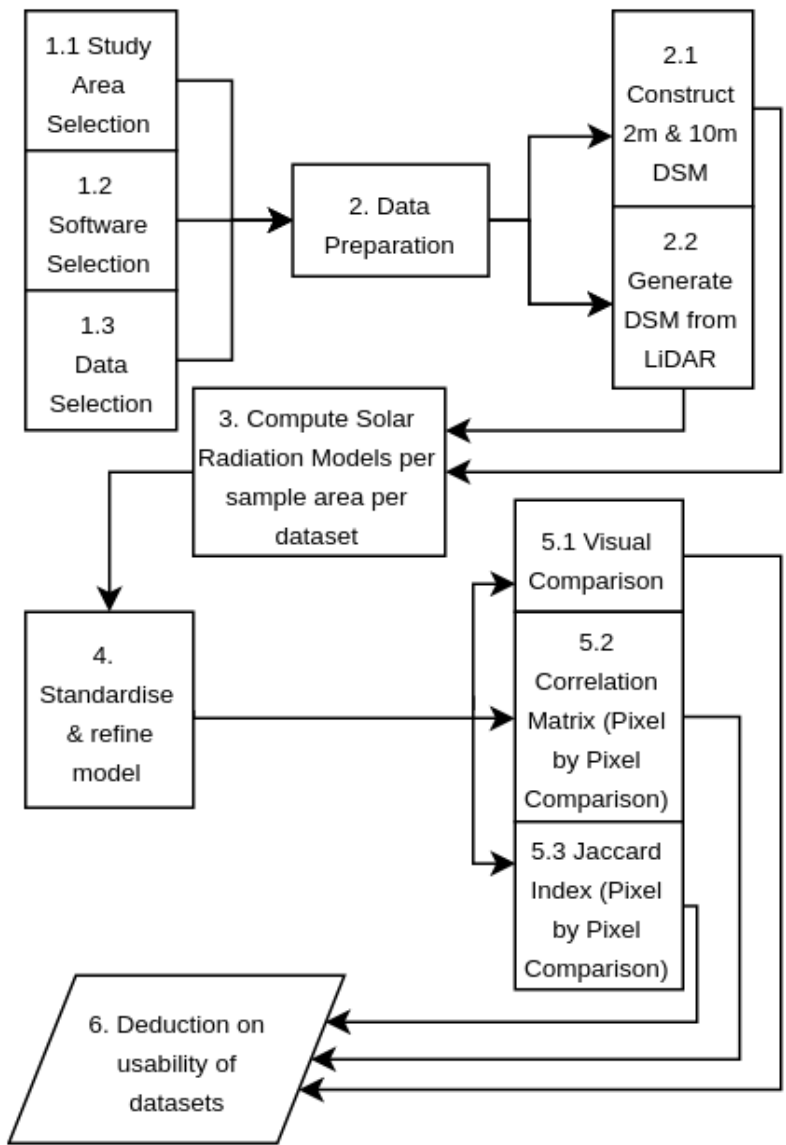

Figure 1. Evaluation process

\subsection{Study area}

Informal settlements vary in structure and density due to their dynamic nature and location. Two informal settlements located in Mamelodi East, City of Tshwane, were selected for this study, namely, Alaska and Phomolong (refer to Figure 2), because of their topographical and dwelling density characteristics.

Alaska is located at the foot of the Magaliesberg on the eastern edge of Mamelodi. The local community named the settlement Alaska, as it is located far from main transportation hubs and the central business district (CBD). Due to the topography of the area (i.e. a steep slope and loose ground), the settlement is not densely populated. The hill casts a shadow over the area that may affect the amount of solar radiation in the settlement.
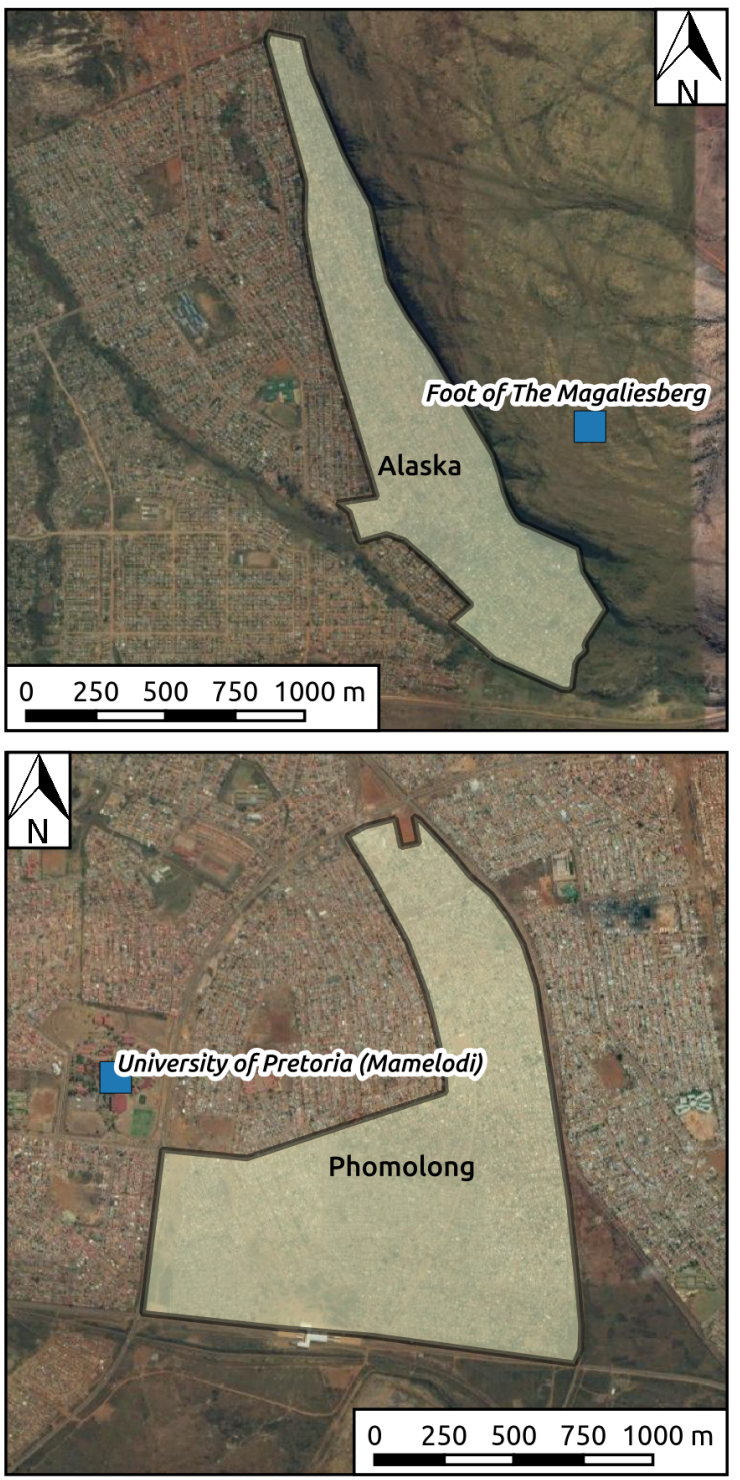

Figure 2. Top: Alaska (top) and Phomolong (bottom) (Data source: Google Maps)

Phomolong is located in Mamelodi East along a main entry route to the township. The Mamelodi campus of the University of Pretoria is located across the road from the settlement, providing employment opportunities (directly or indirectly related to the campus) and easy access to public transportation (taxis). As a result, Phomolong is more densely populated than Alaska. Phomolong is located on a relatively flat surface with little to no obstruction from the sun.

The development of a solar irradiation model is computing intensive and can be time consuming, especially with fine resolution data. Therefore, the solar potential was computed for a sample area in each settlement only. The sample areas were carefully selected to provide a representative result for the entire areas of Alaska and Phomolong respectively. 


\subsection{Software}

The software options available for a solar potential assessment can be divided into two categories, namely computer-aided design (CAD) and GIS.

CAD software provides the capability to analyse 3D data and to generate a solar radiation model based on direct and diffused radiation. CAD software can also simulate the angle step of the sun to create and average the amount of sunlight at any given hour (Freitas et al. 2015). Generally, CAD software does not process data in geographic coordinate systems, but there are exceptions, such as Skelion, a Trimble SketchUp plugin, which uses Google Maps and PVSyst for geographically related solar radiation measurements (Freitas et al., 2015). The main limitation of most CAD software is that their computing models are based on individual dwellings, i.e. the solar radiation model is produced for each individual dwelling. The CAD software is not well suited to producing a solar radiation model for a group of dwellings or for an entire settlement. Furthermore, the resolution of a $2 \mathrm{~m}$ or $10 \mathrm{~m} \mathrm{DEM}$ is too coarse to illustrate the solar potential for individual dwellings in an informal settlement. For these reasons, CAD software was deemed unfit for the purposes of this study (Trimble Inc., 2017; Skelion, 2015).

In contrast to CAD software, GIS software can be used to assess solar potential of both low and high resolution elevation models. The GIS solar radiation tools also offer a three-dimensional perspective with the ability to add different sun angle steps in a geographic coordinate system. GIS software tools for generating solar radiation models take into account supplementary meteorological data, including turbidity, albedo and transmissivity. The latter play a significant role in calculating diffused radiation (Gupta et al., 2012). A summary of the characteristics of solar potential assessment capabilities in CAD and GIS software is provided in Table 1.

\begin{tabular}{|l|c|c|}
\hline & CAD & GIS \\
\hline Dimensionality & 3D & 3D \\
Sun Angle Step & Yes & Yes \\
Geographic coordinate systems & Some & Yes \\
Diffused Radiation & Some & Yes \\
Building Modelling & Yes & Some \\
\hline
\end{tabular}

Table 1. Solar potential assessment capabilities in CAD and GIS

GRASS (Geographic Resources Analysis Support System) GIS is free and open source software for geospatial data analysis, management, and spatial modelling. Among the tools included in the GRASS suite, is the r.sun function, which computes the direct, diffused and reflected solar irradiation for a given day. The r.sun.daily function is an extension of the r.sun function and allows for the computation of solar irradiation for multiple days.

For this evaluation, GRASS GIS was selected because it is free to use, i.e. there is no procurement barrier to its use. When an informal settlement emerges, the solar potential should be assessed as soon as possible. Procurement processes take time and the payment for software presents the opportunity for corruption. This could delay the much-needed solar potential assessment for an informal settlement.

\subsection{Data selection}

Datasets at different costs and resolutions were selected for the evaluation: a freely available 30m DEM; the 30m DEM resampled to a $2 \mathrm{~m}$ and $10 \mathrm{~m}$ DSM respectively, both including building footprints digitized from aerial photographs; and a $1 \mathrm{~m}$ LiDAR dataset procured by the City of Tshwane Metropolitan Municipality. The latter was freely available for the research, but would generally have a cost to it.

The ASTER (Advanced Spaceborne Thermal Emission and Reflection Radiometer) Global DEM at $30 \mathrm{~m}$ resolution was selected for this evaluation, as it is readily accessible, freely available and pre-processed. A $30 \mathrm{~m}$ DEM is appropriate for calculating the solar potential of an area with minimal buildings and/or tall vegetation, i.e. the topography is the primary source of obstruction to direct radiation (Rich and Fu, 1999). Processing a $30 \mathrm{~m}$ DEM is faster than processing DEMs of a higher resolution. However, the usefulness of the outputs is questionable for informal settlements, as the results may be too generalised to use (Lin et al., 2013). Nevertheless, the $30 \mathrm{~m}$ DEM was included in the evaluation to represent the worst-case (or baseline) scenario.

The informal dwellings in the two study areas are generally between $2.5 \mathrm{~m}$ to $5.5 \mathrm{~m}$ wide and $1.9 \mathrm{~m}$ to $2.2 \mathrm{~m}$ in height. Based on the width of dwellings, the following two datasets were created from the $30 \mathrm{~m}$ DEM:

1. A resampled $2 \mathrm{~m}$ DSM, including most building footprints, and representing a common DSM resolution extracted from aerial photographs or LiDAR data

2. A resampled $10 \mathrm{~m}$ DSM, including only the larger building footprints.

\subsection{Data preparation}

A $2 \mathrm{~m}$ DEM was created by converting the $30 \mathrm{~m}$ DEM into a triangular irregular network (TIN). Subsequently, the TIN was converted to a $2 \mathrm{~m}$ DEM. Without the intermediate TIN, the resulting DEM surface is discontinuous or discrete (step-like). The TIN surface has discrete edges but these are not as significant as those in the discrete surface produced from resampling the DEM (Liu and Zhang, 2008; Ramirez, 2006). The step-like discrete surface impacts the results obtained from the solar potential assessment, because each discrete 'step' casts a shadow. When creating the $10 \mathrm{~m}$ DEM it was not needed to first convert the $30 \mathrm{~m}$ DEM to a TIN, as the resampling technique (i.e. Bilinear Interpolation) simply produced a $10 \mathrm{~m}$ DEM with a smooth surface.

The final step for creating the $2 \mathrm{~m}$ and $10 \mathrm{~m}$ DSM was to add the rasterized building footprints to the $2 \mathrm{~m}$ and $10 \mathrm{~m}$ DEMs respectively. The dwelling height was randomly set to a value between 1.9 to $2.2 \mathrm{~m}$. Figure 3 shows the $2 \mathrm{~m}$ DSM. 


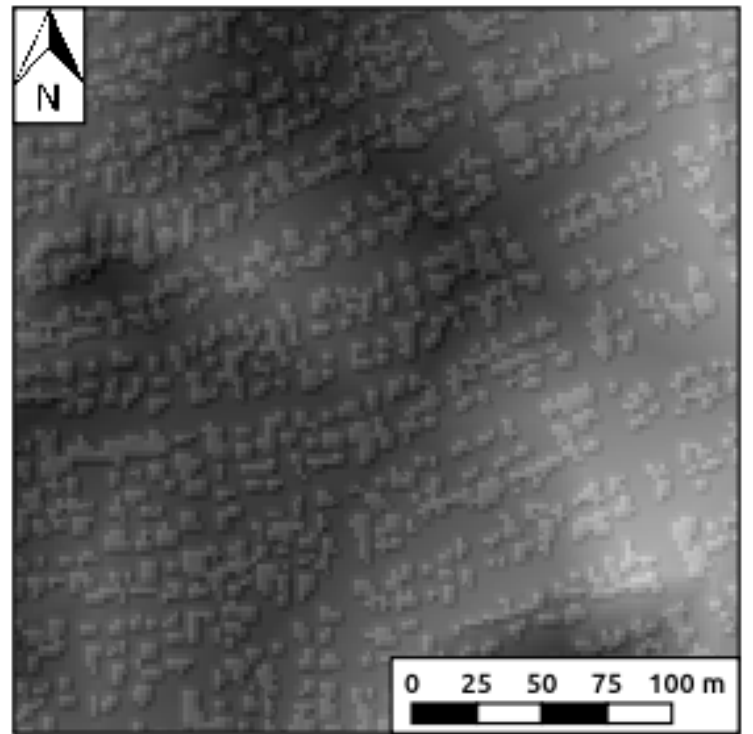

Figure 3. Visualization of the 2m DSM

DSMs are commonly generated from LiDAR point clouds (Liu and Zhang 2008). The vertical accuracy of LiDAR data is said to be between $15 \mathrm{~cm}$ in sparsely populated areas (i.e. with no vegetation) and $27 \mathrm{~cm}$ in areas with dense vegetation (Hodgson and Bresnahan, 2004; Reutebuch et al., 2003). A DSM can be generated from a LiDAR dataset without extensive processing. A non-grounded LiDAR dataset from the City of Tshwane was used for this evaluation. The non-grounded LiDAR was combined with manually digitised building footprints to generate a $1 \mathrm{~m}$ DSM (refer to Figure 4).

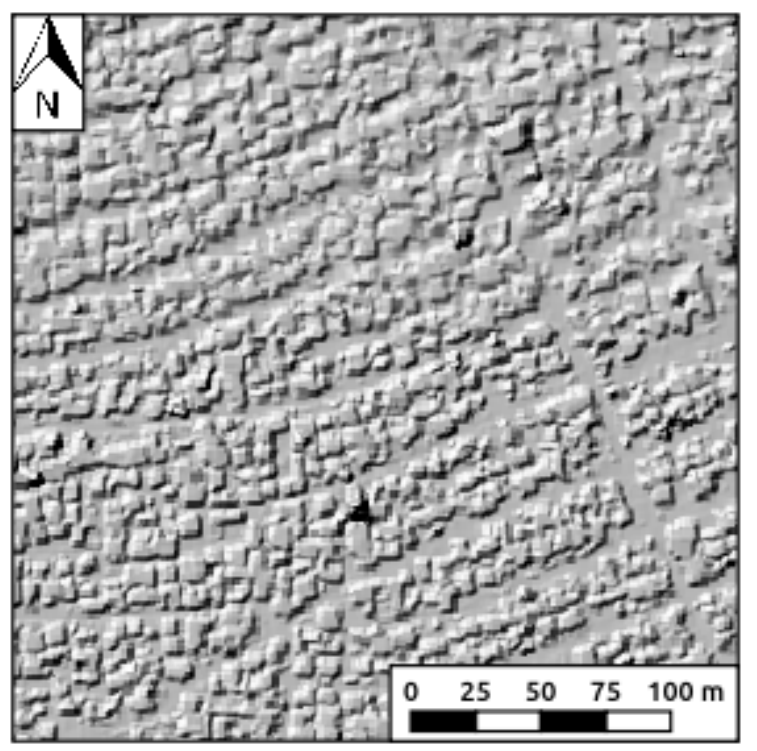

Figure 4. 1m DSM of Phomolong

\subsection{Computing and refining the solar radiation models}

GRASS offers a built-in function, r.sun, for calculating the solar radiation for a given day in a year. The r.sun.daily extension calculates radiation for multiple days in a year. For this evaluation, the r.sun.daily function was used. The parameters used to compute the solar radiation for the four datasets are explained in Table 2.

\begin{tabular}{ll}
\hline \multicolumn{1}{c}{ Input parameter } & \multicolumn{1}{c}{ Value } \\
\hline Aspect & Self-computed by r.sun function \\
\hline Slope & Self-computed by r.sun function \\
\hline Linke turbidity & 3.345 (average seasonal value) \\
\hline Albedo coefficient & 0.177 \\
\hline Lat & Computed from the DEM \\
\hline Long & Computed from the DEM \\
\hline Horizon step & 5 (degrees) \\
\hline Start day & 1 (to start on 1 January) \\
\hline End day & 365 (to end on 31 December) \\
\hline Day step & 1 (for daily recordings) \\
\hline Time step & 0.5 (for half hourly recordings) \\
\hline
\end{tabular}

Table 2. GRASS r.sun.daily parameter values

Linke turbidity and the albedo coefficient are meteorological conditions. Linke turbidity refers to atmospheric haziness or cloudiness (Nguyen and Pearce, 2010), and the albedo coefficient measures the amount of light reflected from the ground (Azar and Teller, 2001; Nguyen and Pearce, 2010). The average annual Linke value for this evaluation was taken for Mamelodi, as recorded by Meteostat and sourced from SoDa (http://www.sodapro.com/). The annual average Albedo value for Mamelodi was obtained from the NASA Research Langley Center for Atmospheric Science (NASA, 2017).

We used two outputs from the r.sun.daily function, namely a sequence of solar potential assessment, one for each day of the year; and a cumulative assessment for the entire period. The solar radiation models produced by the r.sun.daily consider only clear sky conditions, which is not an accurate representation of real world conditions. Applying the Clear Sky Insolation Normalized Clearness Index ( $\mathrm{kC}$ coefficient) corrects the output produced by the r.sun.daily function. The $\mathrm{kC}$ coefficient for Mamelodi was sourced from NASA (2017). The average $\mathrm{kC}$ value for 2017 was 0.675 . Using map algebra, the value was multiplied with the raster surface of Alaska and Phomolong.

The cumulative output of the r.sun.daily function has values in $\mathrm{W} / \mathrm{h} / \mathrm{m}^{2} /$ year (Watt per hour per square meter per year). The $\mathrm{W} / \mathrm{h} / \mathrm{m}^{2} /$ year values were converted to $\mathrm{kWh} / \mathrm{m}^{2} /$ day (Kilowatt hours per square meter per day) by dividing the value for each cell in each raster dataset by 1000 and by 365 .

\subsection{Comparing the solar potential assessments}

The final step in the process was to compare and evaluate the solar potential assessments calculated with the four datasets. The result of the $1 \mathrm{~m}$ DSM was compared to the results produced for each of the other three datasets. Visual comparison of the results was followed by two pixel by pixel comparisons.

The visual comparison was based on multivariate histograms and maps. Using $\mathrm{R}$, and the raster, sp and rdgal libraries, three multivariate graphs were computed, depicting the $\mathrm{kWh} / \mathrm{m}^{2} /$ day of the three sets of resulting datasets. These, and maps, were visually compared to draw final conclusions.

For the pixel by pixel comparison, two methods were used: correlation matrix and Jaccard index. The cell sizes of the resulting solar radiation datasets were converted to be identical ( $1 \mathrm{~m})$ before the correlation matrix could be computed for each comparison. The correlation matrix could then be interpreted to provide information regarding the exact matches of pixel values in $\mathrm{kWh} / \mathrm{m}^{2} /$ day. 
As described by Bouchard et al. (2013), the Jaccard Index is a similarity test that determines the amount of intersection instances between datasets $\mathrm{A}$ and $\mathrm{B}$, denoted by:

(1)

$$
J A C(A, B)=\frac{|A \cap B|}{|A \cup B|}
$$

This is an effective method of investigating the similarity of two raster datasets, since the function can be completed using map algebra.

\section{RESULTS AND DISCUSSION}

\subsection{Visual Comparison}

From the four datasets in this study, the most accurate solar radiation model is produced from the LiDAR derived $1 \mathrm{~m}$ DSM, depicted in Figure 6. This output is the baseline against which the others are compared.

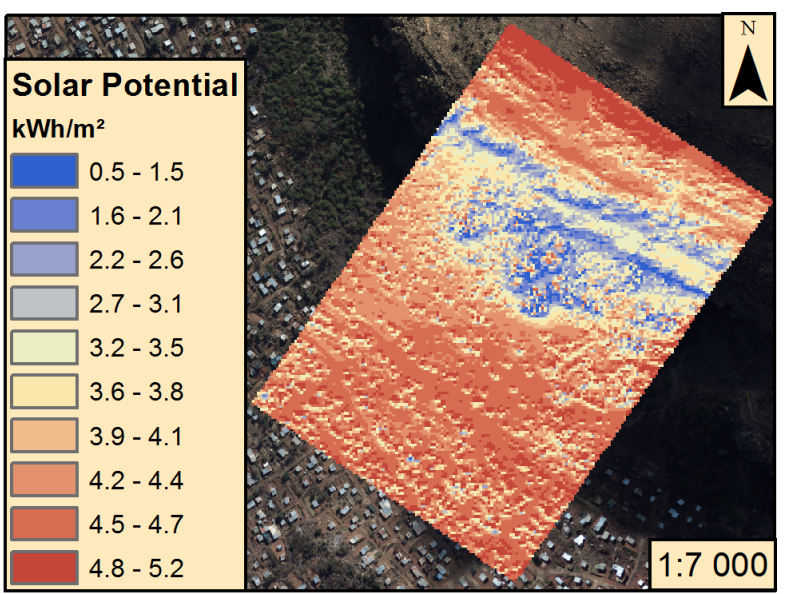

Figure 6. Solar radiation model for Alaska derived from the $1 \mathrm{~m}$ DSM

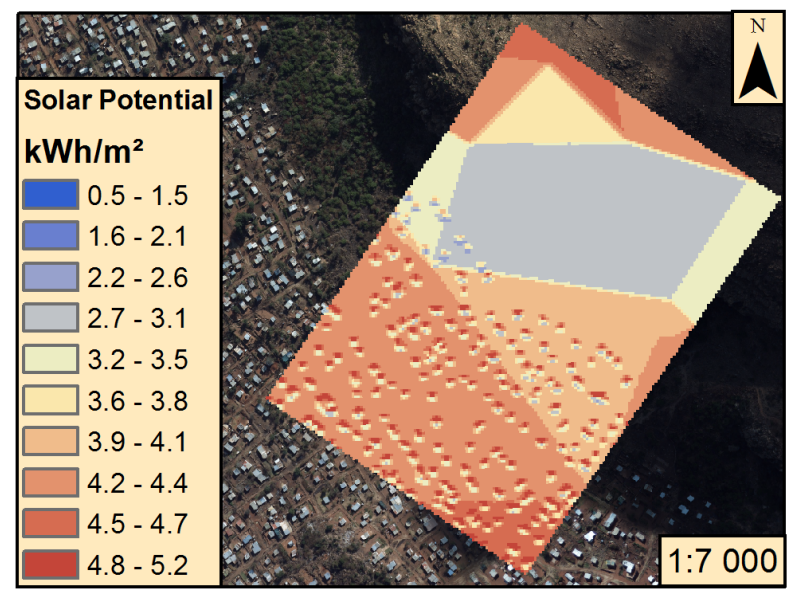

Figure 7. Solar radiation model for Alaska derived from the $2 \mathrm{~m}$ DSM

The $2 \mathrm{~m}$ DSM provides a reasonable indication of the solar distribution within the area, except in the steep hill areas, as seen in Figure 7. Since the $30 \mathrm{~m}$ DEM was first resampled to a raster of $2 \mathrm{~m}$ cell size, then converted to a TIN surface and finally converted back to a raster surface, there is a loss of data quality (Ramirez, 2006).

In Figure 8, each value within the top red circle is identical (depicted in the same colour), because each pixel value in the solar radiation model derived from the $2 \mathrm{~m}$ DSM represents a generalised $\mathrm{kWh} / \mathrm{m}^{2} /$ day value. The solar radiation model derived from the $1 \mathrm{~m}$ DSM (bottom of Figure 8 ) is a more accurate reflection of solar distribution in the area. The data quality loss is more prevalent in Alaska because its topography varies more than that of Phomolong. The TIN surface for the flat topography of Phomolong does not significantly affect the quality of the solar potential assessment.
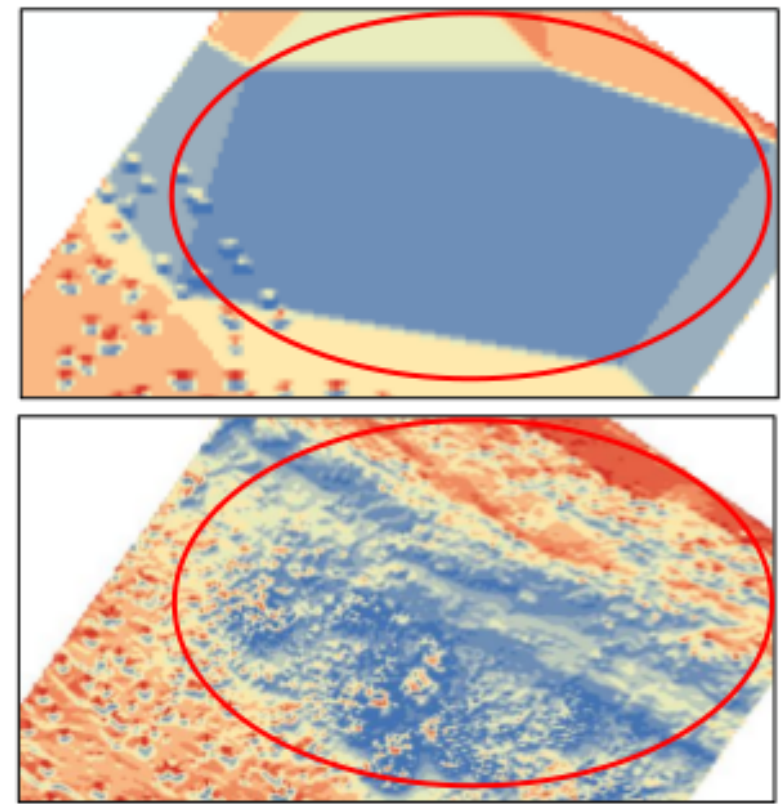

Figure 8. Data quality loss due to TIN conversion when preparing the 2m DSM (top); Quality unaffected with the $1 \mathrm{~m}$ DSM (bottom)

Figure 9 shows that despite the difference in resolution, the solar radiation model for the $2 \mathrm{~m}$ DSM produces a similar range of values for an individual dwelling to the one derived from the $1 \mathrm{~m}$ DSM. The radiation model derived from the 2m DSM does not consider vegetation, but the one derived from the 1m DSM does. The impact of this can be observed in Figure 9: due to the tree to the right of the dwelling, the solar potential values in the bottom image are lower (depicted by the blue grid cells). This emphasises the impact of including vegetation in the DSM for the solar potential assessment.

The solar radiation model derived from the 10m DSM provides a less accurate indication of the solar distribution in Alaska, as seen in Figure 10. Each pixel value is a generalised $\mathrm{kWh} / \mathrm{m}^{2} /$ day value for that specific $100 \mathrm{~m}^{2}$ area (cell). The large cell size causes a discontinuous or discrete (step-like) surface, resulting in an inaccurate estimate of the solar radiation model. Compare, for example, the lower left part of the sample areas in Figure 10 and Figure 6 (derived from $1 \mathrm{~m}$ DSM). The anomaly is present for both Alaska and Phomolong and is confirmed by the descriptive statistics of the pixel by pixel comparisons that follow. 

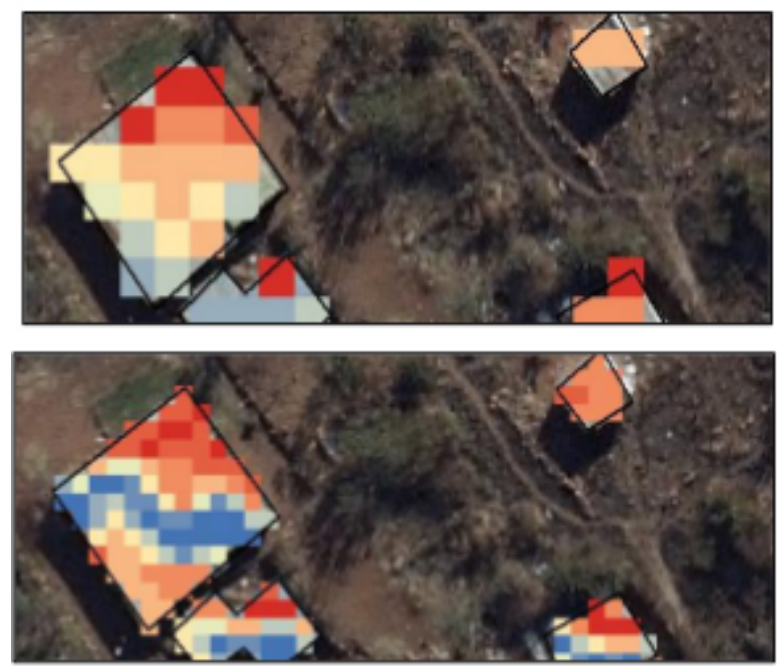

Figure 9. Solar radiation model derived from 2m DSM (top); Solar radiation model derived from 1m DSM (bottom)

Processing the 10m DSM is fast, but the disadvantage of the solar radiation model derived from this model is that the solar radiation for individual dwellings cannot be derived, because more than one dwellings may exist within a $10 \mathrm{~m} \times 10 \mathrm{~m}$ area (cell).

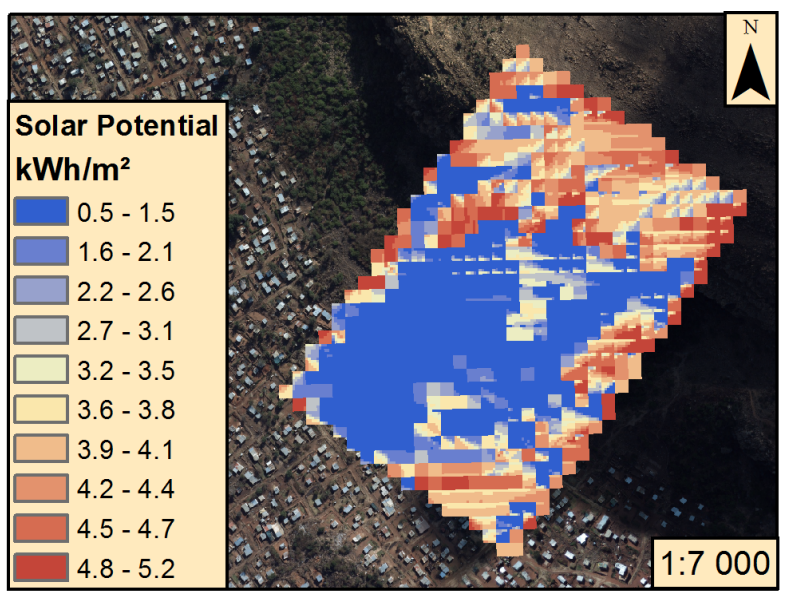

Figure 10. Solar radiation model for Alaska derived from the $10 \mathrm{~m} \mathrm{DSM}$

Deriving a solar radiation model from the $30 \mathrm{~m}$ DEM is not suitable for this study because the cells are too large; individual dwellings and their shadows are not considered. However, the $30 \mathrm{~m}$ DEM serves its purpose for determining solar potential for a much larger area (on a very small scale), e.g. for an entire city or province.

\subsection{Pixel by Pixel Comparison}

Descriptive statistics for each solar radiation model (raster) in Alaska and Phomolong are listed in Tables 3 and 4 respectively. Minimum value represents the smallest pixel value in the raster; maximum represents the largest pixel value; $\bar{x}$ is the average pixel value; $\sigma$ is the standard deviation of pixel values; and the correlation coefficient describes the similarity to the solar radiation model derived from the $1 \mathrm{~m}$ DSM. According to these, the minimum values for solar radiation models derived from the $2 \mathrm{~m}$ and $10 \mathrm{~m}$ DSMs are very similar but higher than for the $1 \mathrm{~m}$ DSM. This is because shadows caused by vegetation in areas where there is a steep slope results in little to no radiation. These shadows are not recognised by the solar radiation model derived from $2 \mathrm{~m}$ or $10 \mathrm{~m}$ DSMS, because vegetation and marginal differences in slope are not included in the $30 \mathrm{~m}$ DEM from which these models were derived.

\begin{tabular}{|l|c|c|c|c|c|}
\hline & Min & Max & $\overline{\mathrm{x}}$ & $\sigma$ & $\begin{array}{c}\text { Correlation } \\
\text { coefficient }\end{array}$ \\
\hline 30m DEM & 0.543 & 2.784 & 2.083 & 0.463 & -0.259 \\
10m DSM & 0.345 & 4.826 & 2.418 & 1.730 & -0.460 \\
\hline 2m DSM & 2.133 & 5.156 & 3.799 & 0.632 & 0.5497 \\
1m DSM & 0.538 & 5.160 & 3.951 & 0.804 & 1 \\
\hline
\end{tabular}

Table 3. Descriptive statistics of the comparisons of the solar radiation model for Alaska

\begin{tabular}{|l|c|c|c|c|c|}
\hline & Min & Max & $\overline{\mathrm{x}}$ & $\sigma$ & $\begin{array}{c}\text { Correlation } \\
\text { coefficient }\end{array}$ \\
\hline 30m DEM & 1.323 & 5.004 & 4.492 & 0.552 & -0.054 \\
10m DSM & 1.804 & 5.164 & 4.470 & 0.517 & 0 \\
\hline 2m DSM & 1.893 & 5.165 & 4.426 & 0.507 & 0.378 \\
1m DSM & 0.909 & 5.164 & 4.547 & 0.382 & 1 \\
\hline
\end{tabular}

Table 4. Descriptive statistics of the comparisons of the solar radiation models for Phomolong

For the $2 \mathrm{~m}$ DSM, the average solar radiation values for both Alaska (between 2 and 4) and Phomolong (approx. 4.4) are similar to those of the $1 \mathrm{~m}$ DSM, indicating that, as expected, the $2 \mathrm{~m} \mathrm{DSM}$ is a realistic representation, albeit less accurate. The standard deviation of the $2 \mathrm{~m}$ derived solar radiation model is less than that of the solar radiation model derived from the $1 \mathrm{~m}$ DSM. The $10 \mathrm{~m}$ DSM and the $30 \mathrm{~m}$ DEM have smaller standard deviations than the $2 \mathrm{~m}$ DSM, confirming that the distribution of values is more clustered and generalised when the resolution decreases.

\section{CONCLUSION}

In this paper, we evaluated the results of solar potential assessments using GRASS for four different datasets: a freely available $30 \mathrm{~m}$ DEM; the $30 \mathrm{~m}$ DEM resampled to a $2 \mathrm{~m}$ and $10 \mathrm{~m}$ DSM respectively, both including building footprints digitized from aerial photographs; and a $1 \mathrm{~m}$ LiDAR dataset procured by the City of Tshwane Metropolitan Municipality. The latter was freely available for this research, but would generally have a significant cost to it. The assessments were done for two informal settlements in the City of Tshwane (South Africa): Alaska, which is nestled on a hill; and Phomolong, a densely populated settlement with a rather flat topography. The assessments show that both settlements obtain sufficient solar energy, despite the irregular topography and high density of dwellings.

The solar potential assessment derived from the 30m DEM was not usable because a single cell included more than one dwelling. Therefore, one cannot assess the solar potential for an individual dwelling. With the $30 \mathrm{~m}$ DEM resampled to $10 \mathrm{~m}$ and $2 \mathrm{~m}$ DSMs respectively, better results are achieved. When comparing the solar potential on roofs of individual dwellings, the values in the solar radiation model derived from the $2 \mathrm{~m}$ DSM are comparable to those of the 1m DSM (created from LiDAR). The 1m DSM created from LiDAR data provides the best results but comes at a significant cost.

The resampling of data and conversion to an intermediate TIN surface reduces the quality of the derived solar assessment, 
especially when the topography (elevation) varies over an area. For a smaller area (e.g. dwelling), this impact is more significant than for a larger area (e.g. entire settlement). Also, the resampled data does not consider shadows cast by vegetation, such as large trees.

The results confirm that solar potential assessments with open source GIS software and freely available data are practically and financially feasible. Following this approach eliminates the need for lengthy and bureaucratic procurement processes and reduces the financial costs of assessing solar potential for informal settlements.

\section{ACKNOWLEDGEMENTS}

We would like to acknowledge the National Research Foundation (NRF) for bursary funding of Luqmaan Hassim, and the City of Tshwane for the aerial photography and LiDAR datasets used in this study.

\section{REFERENCES}

Azar, S., and Teller, J., 2001. Townscope II - A Computer System to Support Solar Access. Solar Energy, 70(3), pp. 187200

Bouchard, M., Jousselme, A., and Doré, P., 2013. International Journal of Approximate Reasoning A proof for the positive definiteness of the Jaccard index matrix. International Journal of Approximate Reasoning, 54(5), pp. 615-626.

Chaves, A., and Bahill, A.T., 2010. Solar Panels derived from LiDAR. ArcUser, pp. 24-27.

Dawood, Z., 2015. Protests over removal of illegal connections, IOL. Available online at https://www.iol.co.za/dailynews/news/protests-over-removal-ofillegal-connections-1882652 (29 April 2018)

Devabhaktuni, V., Alam, M., Depuru, S.S.R., Green, R.C., Nims, D., and Near, C., 2013. Solar energy: Trends and enabling technologies. Renewable and Sustainable Energy Reviews, 19, pp. $555-564$.

Fluri, T.P., 2009. The potential of concentrating solar power in South Africa. Energy Policy, 37(12), pp. 5075-5080.

Freitas, S., Catita, C., Redweik, P., and Brito, M.C., 2015. Modelling solar potential in the urban environment: State-of-theart review. Renewable and Sustainable Energy Reviews, 41, pp. 915-931.

Fuzile, B., 2017. Illegal electricity connections kill 63, Dispatch. Available online

http://www.dispatchlive.co.za/news/2017/06/19/illegalelectricity-connections-kill-63/ (29 April 2018)

Gupta, R., Tiwari, G.N., Kumar, A., and Gupta, Y., 2012. Calculation of total solar fraction for different orientation of greenhouse using 3D-shadow analysis in Auto-CAD. Energy and Buildings, 47, pp. 27-34.

Hodgson, M. E., and Bresnahan, P., 2004. Accuracy of Airborne Lidar-Derived Elevation: Empirical Assessment and Error
Budget. Photogrammetric Engineering \& Remote Sensing, 70(3), pp. 331-339.

Hofierka, J., and Kaňuk, J., 2009. Assessment of photovoltaic potential in urban areas using open-source solar radiation tools. Renewable Energy, 34(10), pp. 2206-2214.

Holm, D., 2006. Renewable Energy Future for the Developing World. White Paper. Available online at http://arge.stanford.edu/courses/2016/ph240/thornton2/docs/ise s-2005.pdf (29 April 2018).

Kakembo, V., and van Niekerk, S., 2014. The integration of GIS into demographic surveying of informal settlements: The case of Nelson Mandela Bay Municipality, South Africa. Habitat International, 44, pp. 451-460.

Khubisa, M., 2017. Canelands residents protest against removal of illegal connections. Phoenix Sun. Available online at https://phoenixsun.co.za/50116/canelands-residents-protestremoval-illegal-connections/ (29 April 2018).

Liang, J., Gong, J., Zhou, J., Ibrahim, A. N., and Li, M., 2015. An open-source 3D solar radiation model integrated with a 3D Geographic Information System. Environmental Modelling and Software, 64, pp. 94-101.

Lin, S., Jing, C., Coles, N.A., Chaplot, V., and Moore, N.J., 2013. Evaluating DEM source and resolution uncertainties in the Soil and Water Assessment Tool. Stoch Environ Res Risk Assess, pp. 209-221.

Liu, W., and Zhang, Z., 2008. Lidar Data Reduction for Efficient and High Quality DEM Generation. The International Archives of the Photogrammetry, Remote Sensing and Spatial Information Sciences, XXXVII(B3).

Moodley, C., 2016. Three electrocuted at informal settlement. Overport Rising Sun. Available online at http://risingsunoverport.co.za/29133/three-electrocuted-atinformal-settlement/ (29 April 2018).

NASA, 2017. Data Center for Surface meteorology and Solar Energy (SSE). Retrieved July 12, 2017, from https://eosweb.larc.nasa.gov/

Nguyen, H.T., and Pearce, J.M., 2010. Estimating potential photovoltaic yield with r.sun and the open source Geographical Resources Analysis Support System. Solar Energy, 84(5), pp. 831-843.

Owen, K.K., and Wong, D.W., 2013. Exploring structural differences between rural and urban informal settlements from imagery: the basureros of Cobán. Geocarto International, 28(7), pp. 562-581.

Paar, P., and Rekittke, J., 2011. Low-cost mapping and publishing methods for landscape architectural analysis and design in slumupgrading projects. Future Internet, 3(4), pp. 228-247.

Ramirez, J.R., 2006. A New Approach to Relief Representation. Surveying and Land Information Science, 66(1), pp. 19-255.

Rautenbach, V., Bevis, Y., Coetzee, S., and Combrinck, C., 2015. Evaluating procedural modelling for 3D models of informal settlements in urban design activities. South African Journal of Science, Volume 111(Number 11/12), 10 Pages. 
Rautenbach, V., Coetzee, S., and Coltekin, A., 2016. Investigating the use of $3 \mathrm{D}$ geovisualizations for urban design in informal settlement upgrading in South Africa. International Archives of the Photogrammetry, Remote Sensing and Spatial Information Sciences (ISPRS Archives), 41(July), pp. 425-431.

Redweik, P., Catita, C., and Brito, M., 2013. Solar energy potential on roofs and facades in an urban landscape. Solar Energy, 97, pp. 332-341.

Reutebuch, S.E., Mcgaughey, R.J., Andersen, H., and Carson, W.W., 2003. Accuracy of a high-resolution lidar terrain model under a conifer forest canopy. Canadian Journal of Remote Sensing, 29(5), pp. 527-535.

Rich, P.M., and Fu, P., 1999. Design and implementation of the Solar Analyst: an ArcView extension for modeling solar radiation at landscape scales. Proceedings of the Nineteenth Annual ESRI User Conference. Creekside Center for Earth Observation, USA.

Richards, R., O’Leary, B., and Mutsonziwa, K., 2006. Measuring quality of life in informal settlements in South Africa. Social Indicators Research, 81(2), pp. 375-388.

Skelion, 2015. Skelion. http://skelion.com/ (29 April 2018)

Sliuzas, R., 2003. Opportunities for enhancing communication in settlement upgrading with geographic information technologybased support tools. Habitat International, 27(4), pp. 613-628.

Trimble Inc, 2017. SketchUp. https://www.sketchup.com/ (29 April 2018) 